Craig, A. B., Martz, D. M., \& Bazzini, D. G. (2007). Peer Pressure to "Fat Talk": Does Audience Type Influence How Women Portray Their Body Image: Eating Behaviors, 8(2), 244-250

Elsevier (ISSN: 1471-0153) doi:10.1016/j.eatbeh.2006.06.006

Keywords: Fat talk; Impression management; Body image

\title{
Peer pressure to "Fat talk": Does audience type influence how women portray their body image?
}

\author{
Ashley B. Craig, Denise M. Martz, and Doris G. Bazzini
}

\begin{abstract}
"Fat talk" describes women discussing their bodies disparagingly for impression management while interacting with one another. This study examined whether college females deliberately alter their self-reported body image according to characteristics of their prospective audience. This study was a mixed experimental design with four audience conditions (private, public, female audience, male audience) as the betweensubjects factor and time across trials as the within-subjects factor using college females as participants $(N=100)$. Pre versus posttest changes on the Body Esteem Scale (BES) and the Body Weight Figure Assessment (BWFA) served as the dependent variables. It was hypothesized that body image would decrease to indicate selfderogation (fat talk) in the public audience and female audience conditions, whereas body image would increase in the male audience condition. These hypotheses were not supported using repeated measures ANOVA. Strengths and weaknesses of the study are discussed.
\end{abstract}

\footnotetext{
ARTICLE

For women, being attractive is more than superficial; attractiveness is a social asset thought to ultimately provide popularity, romantic companionship, and overall increased opportunities across situations (Deaux \& Hannah, 1984). Female attractiveness in Western society is often equated with thinness (Mori, Chaiken, \& Pliner, 1987). This ideal of thinness has been reinforced by the mass media via magazines, television, and popular cultural icons (O'Dea, 1995). The result of this infatuation with the ideal, thin woman has resulted in a normative level of body image discontent among women (Rodin, Silberstein, \& Striegel- Moore, 1984). Furthermore, this emphasis on being thin in Western society has become a frequent theme in the media in American culture
} 
(Nichter \& Vuckovic, 1994). In recent years, news, talk shows, and self-help books seem eager to speak on the issue of losing weight and achieving attractiveness.

Previous research has found that exposure to media's "thin ideal" does have a negative impact on females' reported body esteem and satisfaction (Grogan et al., 1996 and Stice et al., 1994 E. Stice, E. Shupak-Neuberg, H. Shaw and R. Stein, Relation of media exposure to eating disorder symptomatology: An examination of mediating mechanisms, Journal of Abnormal Psychology 103 (1994) (4), pp. 836-840. Abstract | Full Text via CrossRef | View Record in Scopus | Cited By in Scopus (249)Stice et al., 1994), suggesting that such representations are relevant to women's self-concepts. Furthermore, women appear to be particularly sensitive to peers' adherence to and promotion of the thin ideal (Stice, Maxfield, \& Wells, 2003). Indeed, one of the most potent forms of peer pressure to be thin occurs in casual conversations when a thin peer complains about feeling fat and needing to lose weight (Stice et al., 2003). Although this form of social pressure to be thin is arguably indirect (i.e., the intent of the communication is not to persuade), discussions of weight are formal and frequent among women, particularly adolescent girls (Nichter \& Vuckovic, 1994). Nichter and Vuckovic (1994) have labeled such conversations "fat talk" when referring to its role among middle school-aged Caucasian females.

Specifically, fat talk refers to a ritualized conversation or verbal exchange regarding weight. These conversations typically occur between females, most of whom are white and middle-class (Nichter \& Vuckovic, 1994). The most common use of fat talk generally includes the words "I'm so fat." This type of conversation, however, does not typically occur among girls who are, in fact, overweight, but rather among those of average weight and height. Although Nichter and Vuckovic (1994) have described multiple definitions or usages of "fat talk," their version of fat talk as a means of social control (i.e., impression management) will be the focal definition in the current study. For example, if fat talk conversation occurs among a group of females who are expressing discontent about their bodies, it is expected that all females involved will join in and self-derogate as well (Nichter \& Vuckovic, 1994). Thus, there appears to be indirect pressure on girls to self-derogate their bodies in the presence of other girls. Failure to disclose in this way could be interpreted as an admission that a woman feels satisfied with her body and/or is perfect. Such disclosure would risk isolation and rejection. In conclusion, middle school-aged Caucasian females report fat talking to fit in with their peers, even though they are not really overweight. 
Recent research has examined whether females are influenced by peer pressure to be thin. Stice et al. (2003) conducted a study that experimentally manipulated the influence of a thin peer's dialogue regarding weight on college women's body dissatisfaction. They exposed women to a thin, attractive, female confederate who either complained about feeling fat and her need to lose weight (similar to Nichter and Vuckovic's "fat talk" dialogue) or talked about a neutral topic. They found that, although women's affect was not adversely affected by the exposure to "fat talk," body dissatisfaction, per participants' written report, was lower if women were exposed to the thin peer expressing weight concern as compared to the control condition. Although women seem influenced by the body derogation of a peer, it is yet unclear whether women also feel pressure to self-derogate about their own weight in these types of interpersonal circumstances.

One descriptive study showed that both female and male college students were cognizant of the societal pressure for women to present themselves as having poor body esteem to other women during conversations of fa talk (Britton, Martz, Bazzini, Curtin, \& LeaShomb, in press). When given a written scenario depicting a fat talk circumstance among college females, both female and male study participants were significantly more likely to report they thought the typical woman would be perceived as most attractive to women if she self-derogated her body in such a situation as compared to responding in two other ways: remaining silent/providing no information or selfaccepting her body. This study also found an interesting gender twist. When presented with a female target across those same three self-presentation scenarios, a significantly higher number of both male and female study participants reported that the woman would be more attractive to men if she self-accepted rather than if she remained silent or self-derogated. Thus, all participants predicted that the target's social attractiveness would vary by the type of response she made and the gender of her audience. A study by Britton et al. (in press) however, was descriptive, and while supporting the norm of fat talk as impression management, it did not assess this construct using an experimental method.

Impression management studies explore how individuals construct an impression of themselves to others by manipulating their actions, appearance, and speech (Schlenker, 1985). Furthermore, impression management can be used as a conceptual model of understanding the differences between behaviors occurring in all-female interactions versus female-male interactions. The present analog study, in addition to examining the impression management aspect of body image experimentally, examined two issues beyond the existing literature. First, it addressed whether or not women 
manipulate their body esteem as a form of impression management in front of an audience (i.e., previous social psychological research has found that participants will manipulate their impression management on paper given a particular believed audience; e.g., Tyler \& Feldman, 2005).

Second, it explored, using pretest and posttest measures, whether females would deliberately alter their reported body image any differently based on gender of the audience. Research suggests that women are less likely to present themselves negatively to men than to women (Rowatt, Cunningham, \& Druen, 1999). For example, Rowatt et al. had female participants look at "prospective dates" that varied in physical attractiveness and were asked to describe their own attributes, in writing, to each of the individuals. The authors found that when presented with a man who is slightly above average in attractiveness, women were significantly more likely to present themselves favorably across multiple domains as compared to a man of below average physical attractiveness. In another study, pairs of participants and confederates took part in a "get acquainted" exercise, discussing neutral topics such as the last trip either had taken or their fondest childhood memory (Mori et al., 1987). Confederate/participant pairs fit one of four conditions: 1) male/male, 2) male/female, 3) female/female or 4) female/male. While participating in the getting acquainted exercise, they were allowed to eat candy $\mathrm{M}$ and $\mathrm{Ms}$, the consumption of which was monitored by experimenters. Additionally, the participants were asked to label their partner as either "desirable" or "undesirable." Mori et al. found that males consumed more candy while with a desirable versus undesirable partner regardless of gender. The opposite was true for females who ate considerably less candy in front of a desirable versus undesirable partner regardless of gender, especially when her femininity had been threatened (Mori et al., 1987). Hence, this research suggests women will impression manage differently than men depending on gender of the audience.

In summary, there is clear evidence that women feel societal pressure to be thin from both media and peers. What has been largely ignored is whether women feel pressure to self-derogate about body image, even if they actually are satisfied with their body appearance. If women feel greater pressure to self-disparage about their bodies as a result of a norm among women to vocalize dissatisfaction, they should engage in more body derogation in front of other women as compared to men.

The present study empirically tested whether women impression manage their written reported body image differently depending on audience type. The design was a Time 
(pretest v. posttest) X Type of Audience (private, public, female audience, male audience) mixed-subjects experimental design with three measures of body image as the dependent variables. The private condition served as the absolute control with no change in reported body image expected for this group. The female and male audience conditions assessed the impact of gender-specific audiences on impression management. An interaction was hypothesized whereby reported body image was expected to change in the direction of self-derogation (fat talk) in the female audience condition, yet change in a more self-accepting direction (opposite of fat talk) in the male audience condition between pretest and posttest.

Given that the majority of research on peer influence on fat talk and its potential consequences has been ethnographic in nature, we chose to experimentally manipulate the context of these types of interactions. We agreed with Stice et al. (2003) that using an experimentally-manipulated context of investigation (in this case audience type on the tendency for women to impression manage about their body esteem) allows the researcher to determine that "the perceived pressures to be thin are not solely in the eye of the beholder" (p.110). Nichter and Vuckovic's (1994) previous research identified fat talk within the context of casual conversations among adolescent girls. However, operationally defining fat talk within an experimental setting presented an interesting challenge. That is, casual conversation in such a context is difficult to induce due to the more formal nature of the setting. Additionally, this study sought to capture the selfpresentational motive of body derogation or enhancement to augment impression management. We reasoned that utilizing a measure that enabled a woman to systematically address a variety of her physical attributes would allow for a more comprehensive analysis of whether fat talk pertains to specific aspects of the body, or a more global statement of dissatisfaction. Therefore, fat talk was operationally defined via temporal changes in self-reports on the Body Esteem Scale (Franzoi \& Shields, 1984) and the Body Weight Figure Assessment Scale (Thompson \& Gray, 1995). Such an approach is consistent with other studies that have utilized self-report measures to examine self-presentation strategies (e.g., Rowatt et al. (1999) adapted items on two popularly utilized love and androgyny assessments to assess the degree of discrepancy between participants' own self-reported propensity for a given dimension as compared to their self-presented propensity for the dimension to a prospective dating partner).

\section{Method}

\subsection{Participants}


One hundred female college undergraduates recruited from the undergraduate, psychology research pool at a medium-sized southeastern university served as participants and received extra credit. The sample was predominantly non-Hispanic, Caucasian (96\%), with an average age of 18 (range 17-22). This study adhered to all ethical guidelines of the American Psychological Association (2002) and was approved by the university's Institutional Review Board on October 18, 2004.

\subsection{Materials}

\subsubsection{Body esteem scale (BES)}

The BES (Franzoi \& Shields, 1984) is a 5-point Likert scale questionnaire used by research participants to rate 35 of their physical characteristics. The 5-point Likert scale defines 1 as being "strong negative feelings" and 5 being "strong positive feelings." The BES has an internal validity of alpha $=.81-.86$ across the 35 physical characteristics (Franzoi \& Shields, 1984). The BES was administered twice to ascertain if reported body esteem changed across time: at baseline as a pretest and after the manipulated type of audience. The BES has a possible range of scores from 35 to 175, with high scores indicating greater esteem and lower scores signifying less esteem.

\subsubsection{Body weight figure assessment (BWFA)}

Thompson and Gray's (1995) Body Weight Figure Assessment depicts 10 female images, each with a slightly different gradations from thinner to heavier. These images are labeled from 1 to 10 and participants are asked to decide which image best represents their current figure and their ideal figure, creating two separate dependent variables. The current figure ratings are strongly correlated with reported weight of subjects $(r=.71)$. The BWFA has high reliability with alpha $=.78$ as well as a test-retest reliability of $97.6 \%-98.0 \%$ for the female drawings (Thompson \& Gray, 1995).

\subsection{Procedure}

Participants were randomly assigned to one of four conditions in approximate groups of 20 based on counter-balanced study sign-up times. Upon arriving to the study, participants signed an informed consent form. Participants were then administered a packet of questionnaires including the BES and BWFA. After completing the first set of questionnaires, the participants engaged in a 5-minute filler task consisting of a word search puzzle to serve as a distraction from the content of the pretest surveys. After the 
filler task was completed, each group (per earlier random assignment) was told that they would either simply fill out the questionnaires a second time (Private Condition) or they would fill out a second set of questionnaires that would then be shown to either of two groups - a female or male audience. In order to enhance the experimental realism of the procedure, the participant was told that this group of women or men would be evaluating the information. By doing so, we wanted to make impression management a more relevant concern for the participants. The following are the specific conditions that resulted:

\subsubsection{Private condition}

Participants were again told that their information would remain anonymous and that only the study code would be known to the proctor who would not be the researchers who would see their forms at the time of data analyses.

\subsubsection{Public condition}

Participants were told that the information that they provided in this second session would be shared with a group of people who would make judgments about them based on their responses to the questionnaire items.

\subsubsection{Public-female-audience condition}

Participants were told that the information that they provided in this second session would be shared with female RAs who would make judgments about them based on their responses to the questionnaire items. Then pictures of four attractive women, embedded within a power point slide, was shown on a large classroom screen to depict the female RAs.

\subsubsection{Public-male-audience condition}

Participants were told that the information that they provided in this second session would be shared with male RAs who would make judgments about them based on their responses to the questionnaire items. Then pictures of four attractive men, embedded within a power point slide, was shown on a large classroom screen to depict the male RAs. 
A pilot study was conducted to determine if the models were, indeed, considered to be attractive. Eighty college students ( $n=53$ females; $n=27$ males), who were primarily Caucasian (90\%) of average age of 20.6, were shown pictures of the four Caucasian females and four Caucasian males (the RAs who would make judgments about them as described above) and asked to rate each from a Likert scale where 1 was "very unattractive" and 10 was "extremely attractive." The mean attractiveness for the females was $6.2(S D=0.97)$ and the mean for the males was $5.7(S D=1.19)$. ANOVA found no differences between the genders and their perceptions of these females RA's attractiveness, $\mathrm{F}(1,79)=1.11, \mathrm{p}=.294, \mathrm{np} 2=.01$. However, the female versus male participants found the male RA's attractiveness to be higher, $F(1,79)=5.8, p=.018$, пр2 $=.07$.

\section{Results}

A time (pre v. post) by condition (private, public, female audience, male audience) mixed-subjects design was used in this study with audience as the between-subjects variable, time as the within-subjects variable, and body image as the dependent variables. Contrary to prediction, analyses of the BES found no time by condition interaction, $\mathrm{F}(3,96)=.378, \mathrm{p}=.769, \mathrm{np} 2=.01$. Furthermore, there were no significant effects for time, $F(3,96)=.000, p=.989, \eta p 2=.00$. See Table 1 for means and standard deviations.

Table 1

Mean body esteem scale score based on type of audience and time

\begin{tabular}{|c|c|c|c|c|c|}
\hline Time 1 & Mean & SD & Time 2 & Mean & SD \\
\hline Private & 128.60 & 18.56 & Private & 129.35 & 20.86 \\
\hline Public audience & 124.27 & 21.22 & Public audience & 122.64 & 22.68 \\
\hline Female audience & 120.84 & 20.18 & Female audience & 122.16 & 20.54 \\
\hline Male audience & 112.09 & 21.22 & Male audience & 111.59 & 21.57 \\
\hline
\end{tabular}

ANOVA also produced null effects for the other dependent variables. Despite the hypotheses, the condition by time interaction was not significant for either the current BWFA, $F(3,96)=1.36, p=.261, n p 2=.41$, nor the ideal BWFA, $F(3,96)=.210, p=$ $.889, \mathrm{np} 2=.007$. Additionally, there was no significant time effect found for either the current BWFA, $F(1,96)=.135, p=.714, n p 2=.00$, nor the ideal BWFA, $F(1,96)=$ 
$.137, p=.712, n p 2=.00$. See Table 2 for mean ratings for current body figure and Table 3 for mean ratings for ideal body figure.

Table 2

Mean body weight figure assessment - current scores based on type of audience and time

\begin{tabular}{llllll}
\hline Time 1 & Mean & SD & Time 2 & Mean & SD \\
\hline Private & 4.55 & 1.76 & Private & 4.55 & 1.76 \\
Public audience & 5.39 & 1.46 & Public audience & 5.48 & 1.40 \\
Female audience & 4.80 & 1.29 & Female audience & 4.96 & 1.60 \\
Male audience & 6.36 & 1.84 & Male audience & 5.95 & 1.99 \\
\hline
\end{tabular}

Table 3

Mean body weight figure assessment - ideal scores based on type of audience and time

\begin{tabular}{lllllc}
\hline Time 1 & Mean & SD & Time 2 & Mean & SD \\
\hline Private & & 1.34 & Private & 3.70 & 1.34 \\
Public audience & 4.09 & 1.07 & Public audience & 4.24 & 1.37 \\
Female audience & 3.64 & 0.91 & Female audience & 3.68 & .095 \\
Male audience & 4.5 & 1.34 & Male audience & 4.45 & 1.22 \\
\hline
\end{tabular}

\section{Discussion}

This study explored the impression management component outlined in Nichter and Vuckovic's (1994) five explanations of fat talk using an experimental research design. Nichter and Vuckovic proposed that women participate in fat talk as a means of adhering to indirect peer pressure where the norm is to speak negatively about one's body. Britton et al.'s research (in press) supported Nichter and Vuckovic's conclusions on middle school-aged females by demonstrating that both female and male college students would expect that, in a fat talk situation, a target female would respond by selfdegrading her body image. However, they also believed that a male would prefer the target female if she self-accepted in a fat talk situation. The present analog study sought to test the hypothesis that a female should report a more negative body image in the presence of a prospective female audience, yet report a more self-accepting body image in the presence of a male prospective audience. These hypotheses were not supported. Indeed, the college female's self-reports of body image esteem did not vary as a function of time or audience, results which appear inconsistent with both Nichter and Vuckovic (1994) and Britton et al. 's (in press) research. 
The most parsimonious reason for these failed hypotheses is that this analog study lacked the social realism to invoke impression management consistent with fat talk. For instance, Gapinski, Brownell, and LaFrance (2003) describe a type of body

objectification called "state self-objectification" which is dependent on situational factors. They argued that state self-objectification occurs only in the presence of real observers or when a person perceives an imaginary audience and presents the threat of appearance evaluation. For example, Gapinski et al. (2003) found that women trying on a bathing suit were more comfortable to a female confederate's fat talk than women trying on a sweater. Hence, fat talk may have a time and a place. By contrast, we did not make the nature of the audience's evaluations clear to participants. Therefore, women may not have felt the appropriate situational pressure to evoke the fat talk norm. Furthermore, Mori et al. (1987) found that women only engaged in impression management by controlling food intake if their femininity had been threatened. Future studies might consider manipulating threat to femininity as an additional variable to more realistically engage fat talk concerns, as well as actual audience rather than just pictures of evaluators. For instance, Gapinski et al. (2003) used an actual female confederate who either spoke disparagingly about her body (fat talk condition) in the clothes or about her terrible day (control condition). They found that women wearing bathing suits reported less negative emotion when hearing the fat talk responses as compared to the control response and that the opposite was true for the women wearing sweaters. That is, they reported more negative emotions when they heard the confederate engage in fat talk as compared to the control response. Gapinski et al.'s findings suggested that there may be situations in which women are uncomfortable with fat talk, a proposition that has not really been explored to date. The use of a more natural setting like the one in the Gapinski et al.'s study may enable more ecologically valid future explorations of the present study's hypotheses.

Another possible reason for women's failure to engage in fat talk could be due to the manipulation. There was no manipulation check performed as a part of the experiment, and thus, it is unknown as to whether or not participants gave the manipulation enough attention to illicit a desire for impression management. Furthermore, a previous pilot study found that the male RAs depicted in the pictures, who were supposed to evaluate the participants, were rated less attractive than the female RAs depicted in the pictures. It is possible that women would be more motivated to impression manage in social circumstances in which they consider their male evaluators to be extremely, rather than average, in attractiveness. Additionally, a classroom lab setting like the one created in this study may be too artificial and not accurately represent a setting that evokes potent impression management concerns. This phenomenon is easily observable on a college 
campus seeing how college students "dress down" for classes but "dress up" for social functions.

Furthermore, fat talk is a phenomenon that occurs verbally, and likely nonverbally, in social situations (Nichter \& Vuckovic, 1994). The present study used a written, selfreport of body image, therefore potentially hindering external validity, for the sake of internal validity, in this fat talk situation. Whereas this served as a fairly systematic operational definition of impression management among females' attributes, it may be that the global report of body dissatisfaction in a fat talk context can not be dissected into individual or component parts. Albeit others have used written, self-report assessments of self presentation such as deliberately manipulating one's written attributes depending on the prospective evaluation of an attractive versus unattractive man to view (Rowatt et al., 1999), fat talk may be a style of conversation, not a list of one's attributes or assessment of one's physique. Hence, future research should explore more creative and externally valid methods of manipulating the peer pressure components of fat talk.

The current investigation is one of the first to experimentally manipulate whether women feel pressure to manipulate their body image or engage in fat talk depending on their social audience. A promising implication for the fact that college females in our sample did not alter their body image presentation based on type of audience could be that the norm to self-derogate one's body may be changing in a more positive direction. Additionally, this norm may be pronounced for young teenage females (i.e., Nichter and Vuckovic's sample), but may weaken in the late teens or early twenties. Future research that creates more socially realistic experimental manipulations of fat talk will help to determine its significance in social circles for college females.

\section{References}

American Psychological Association (APA), 2002 American Psychological Association (APA). (2002). APA Ethics Office. Retrieved March, 2004 from http://0www.apa.org.wncln.wncln.org/ethics/. 
Britton et al., in press Britton, L. E., Martz, D. M, Curtin, L., Bazzini, D. G., Curtin, L., \& LeaShomb, A. (in press). Fat talk a self-presentation of body-image: Is there a social norm for women to self-degrade? Body Image: An International Journal of Research.

Deaux and Hannah, 1984 K. Deaux and R. Hannah, Courtship in the personal columns: The influence of gender and sexual orientation, Sex Roles 11 (1984), pp. 363-376.

Franzoi and Shields, 1984 S.L. Franzoi and S.A. Shields, The Body Esteem Scale: A multidimensional structure and sex differences in a college population, Journal of Personality Assessment 48 (1984) (2), pp. 173-178.

Gapinski et al., 2003 K.D. Gapinski, K.D. Brownell and M. LaFrance, Body objectification and "fat talk": Effects of emotion, motivation, and cognitive performance, Sex Roles 48 (2003) (9/10), pp. 377-388.

Grogan et al., 1996 S. Grogan, Z. Williams and M. Conner, The effects of viewing same gender photographic models on body-esteem, Psychology of Women Quarterly 20 (1996), pp. 569-575.

Mori et al., 1987 D. Mori, S. Chaiken and P. Pliner, "Eating Lightly" and the self presentation of femininity, Journal of Personality and Social Psychology 53 (1987) (693), p. 702.

Nichter and Vuckovic, 1994 M. Nichter and N. Vuckovic, Fat Talk. In: N. Sault, Editor, Many mirrors: Body image and social relations, Rutgers University Press, New Brunswick, NJ (1994), pp. 109-131.

O'Dea, 1995 J.A. O'Dea, Body image and nutritional status among adolescents and adults - a review of the literature, Australian Journal of Nutrition and Dietetics 52 (1995), pp. 56-68. 
Rodin et al., 1984 J. Rodin, L. Siberstein and R. Striegel-Moore, Women and weight: A normative discontent, Nebraska Symposium on Motivation 32 (1984), pp. 267-307.

Rowatt et al., 1999 W.C. Rowatt, P.B. Cunningham and P.B. Druen, Lying to get a date: The effect of facial attractiveness on the willingness to deceive prospective dating partners, Journal of Social and Personal Relationships 16 (1999) (2), pp. 209-223.

Schlenker, 1985 B.R. Schlenker, Identity and self-identification. In: B.R. Schlenker, Editor, The self and social life, McGraw-Hill, New York (1985), pp. 65-99.

Stice et al., 2003 E. Stice, J. Maxfield and T. Wells, Adverse effects of social pressure to be thin on young women: An experimental investigation of the effects of "Fat Talk", International Journal of Eating Disorders 34 (2003), pp. 108-117.

Stice et al., 1994 E. Stice, E. Shupak-Neuberg, H. Shaw and R. Stein, Relation of media exposure to eating disorder symptomatology: An examination of mediating mechanisms, Journal of Abnormal Psychology 103 (1994) (4), pp. 836-840.

Thompson and Gray, 1995 M.A. Thompson and J.J. Gray, Development and validation of a new body image assessment scale, Journal of Personality Assessment 64 (1995) (2), pp. 258-269.

Tyler and Feldman, $2005 \mathrm{~J}$. Tyler and R. Feldman, Deflecting threat to one's image: Dissembling personal information as a self-presentation strategy, Basic and Applied Social Psychology 27 (2005) (4), pp. 371-378. 